\title{
Modelling railway bridge degradation based on historical maintenance data
}

\author{
Bryant Le and John Andrews \\ Nottingham Transportation Engineering Centre, University of Nottingham
}

\begin{abstract}
As structure deteriorates with age and use, it is necessary to devise a maintenance plan to control their states in a cost effective way. In order to evaluate the effectiveness of alternative maintenance strategies their success must be measured by their ability to control the structure condition. The condition can be expressed for either the entire structure or for the components which make up the structure. A problem is how to express this condition. This is a particular problem for bridges where there can be several deterioration mechanisms taking place and there is no clear way of measuring the current state of either the structure of its elements. One approach to defining the condition of bridges is to use condition scores or condition indices, for the infrastructure owners, it is it is desirable that they understand how their population of assets is changing over time. For bridges this has involved providing a condition rating for each structure based on observation and by tracking the changes in the distribution of structure condition for population over time. The current maintenance strategy can then be shown to be inadequate (leading to deteriorating population condition), adequate (producing a stable population condition) or effective and resulting in an improving population condition.
\end{abstract}

There have been a variety of bridge condition scoring systems that have been devised by different infrastructure owners in both the highway and railway sectors. Whilst these scores are not devised to be used in detailed maintenance modelling, due to the lack of alternative data they have frequently been used in this manner. This paper addresses the problems of using this data for bridge degradation modelling and proposes an alternative method to model the degradation of bridge elements using historical work done data. The deterioration process is modelled by a Weibull distribution that governs the time a component deteriorates to a degraded condition state following a repair. The method is demonstrated on real historical maintenance data where the analyses of the deterioration processes of several bridge main bridge components are presented.

Keywords: bridge, asset management, degradation modelling, lifetime analysis, historical work done, Weibull distribution. 


\section{Introduction}

States of bridges or bridge elements are commonly allocated discrete numbers that are associated with a specific condition. These scores/ratings are recorded after an inspection, thus the degradation process of an asset is reflected by the changes of these scores over time. In the USA, following the collapse of the Ohio River Bridge, West Virginia in 1967, the National Bridge Inspection Standard (NBIS) was developed to regulate policy regarding inspection procedures, inspection frequencies and the maintenance of state bridge assets. Highway bridges are inspected annually or more often as necessary, bridge inspectors are required to assign a condition rating $(C R)$ to bridge elements based on the visual inspection. The range of CRs is from 0 to 9 with 0 being 'failed' condition and 9 being 'excellent' condition [1]. These CR data are recorded in the National Bridge Inventory (NBI) to judge bridges' conditions.

Several bridge models have been developed to model the deterioration rates by using these condition data over the last three decades. These models define the model states based on the condition rating and therefore, have 10 models states which correspond to each condition rating [2-5]. There are also some models which reduce the number of model states by choosing a threshold condition that is considered worst in the model but not necessarily the worst condition recorded in the condition rating system ${ }^{[6-9]}$. For example, a condition rating 3 is considered worst acceptable state in the deterioration model, although there are 10 condition states in the CR system [10]. These models employed the Markov approach to model the deterioration process of bridge elements by estimating the probability of transitioning from one condition state to another over multiple discrete time intervals. Markov models capture the uncertainty and randomness of the deterioration process accounting for the present condition in predicting the future condition. Overall, Markov models are the most popular in modelling bridge asset deterioration process, this is because it is relatively simple to allow a fast and adequate study using the condition rating data.

Also based on these condition rating data, there are time-based models [7, 11, 12] that have been developed to model the statistical distributions for the duration that a bridge element will reside in any of the conditions. The data required for these models samples of the time to a specified condition event. By gathering these duration times, a distribution is fitted. Since the bridges are inspected after a specified interval, the exact transition event is not observed and hence it is often assumed that the transition event occur at midpoint between inspection dates. This introduces bias in the duration times that lead to errors in the accuracy of the modelled degradation process. 
In the UK, railway bridges managed by Network Rail have been assessed using the Structure Condition Marking Index (SCMI) to rate the condition taking values ranging from 0 to 100 [13]. A bridge model was also developed to manage these assets based on the Markov approach. Depending on a particular asset, the bridge model has either 10 or 20 states, these states corresponds to 10 or 20 condition bands, each representing 10 or 5 SCMI scores. The collection of the SCMI scores started in 2000, however with more than 30,000 bridges in operation and inspection every 6 years, the data are sparse. Most of the structures only contain one set of scores over time making the determination of the degradation process of bridge asset very difficult to assess. Furthermore, the SCMI system like all scoring indices, the data is subjective and depends on the inspectors.

Condition assessment of the bridges is conducted through visual inspection and is described by subjective indices. The condition of the bridges is typically rated by this idealised system, however the bridge condition score system is inadequate to provide a sound study of the bridge element deterioration process [14]. Most of the developed bridge models used by management authorities manage bridge assets based on these subjective condition indices and make maintenance decisions without considering the effects of maintenance on these scores. In many deterioration modelling studies, rises in the score are usually removed, this means that the effect of maintenance is often ignored $[15,16]$ also discussed the use of the condition rating and concluded that this is not adequate as a performance indicator as it does not reflect the structure integrity of a bridge nor the improvement needed. The condition rating is a subjective evaluation by bridge inspectors with the reliability of the ratings dependent on the experience of the inspectors ${ }^{[17]}$.

This paper proposes a method of modelling the asset deterioration process using historical work done data as an alternative to condition rating data. This provides a fresh approach to asset degradation modelling that captures the effects of maintenance on asset condition and a way to exploit other data available other than condition rating data. The approach involves constructing a timeline of all historical work done of a bridge element and analysing the time it takes a component to reach these intervention conditions. As these intervention actions are triggered by a certain level of defect, the degradation process to these degraded states can be statistically determined. The deterioration process of a bridge element is then described by a statistical distribution of its degradation times to specified degraded states. The analysis methodology will be discussed in detail and the application of the method is also demonstrated. The analysis is conducted on real historical data. The data used contains historical maintenance records of the bridge elements, including the inspection dates. The data by its nature, is of poor quality and sparse in quantity. It does however represent a large data source for UK 
bridges and has, as such, been used to determine as accurately as possible the deterioration of bridge elements. The degradation results for several bridge main components are also reported.

\section{Intervention actions and related condition states}

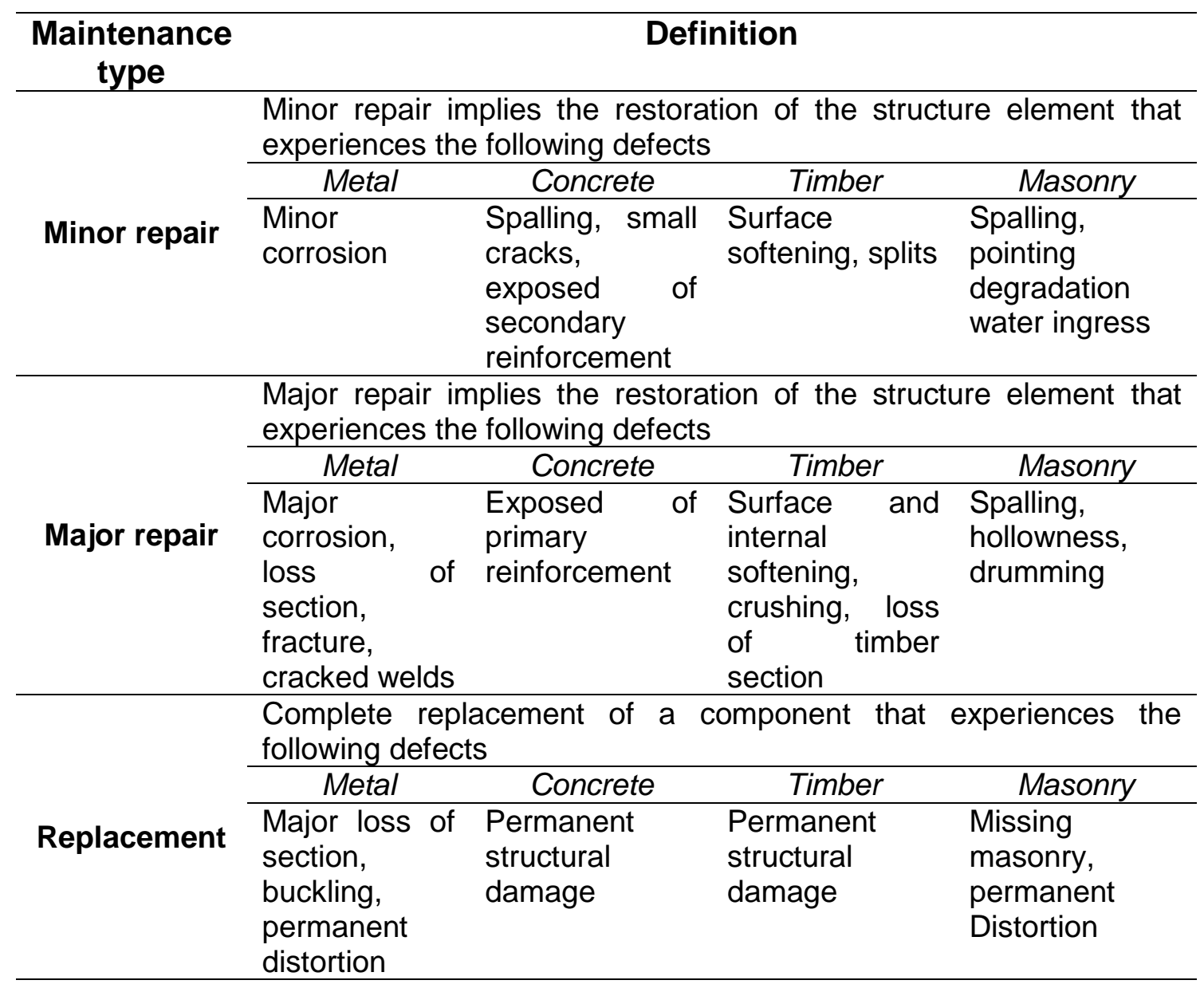

Table 1: Maintenance types definitions

As the condition of a bridge component deteriorates over time, structural defects appear from which it is possible to repair the condition through the appropriate intervention action. Different bridge components experience different degradation processes, thus the maintenance actions required for these components would be different. By grouping the data according to the maintenance duration and cost, maintenance actions are categorised as: minor repair, major repair, and replacement. The precise definitions of these are given

in

Table 1. It shows that the intervention action is triggered by the severity and extent of defects, thus by relating these maintenance actions to the degradation states of the component, four component conditions can be defined that are: 
1. The 'as new' state where the component condition requires no interventions;

2. The good state where the component condition requires minor interventions;

3. The poor state where the component condition requires major interventions;

4. The very poor state where the component condition requires replacement.

\section{Available data and data processing}

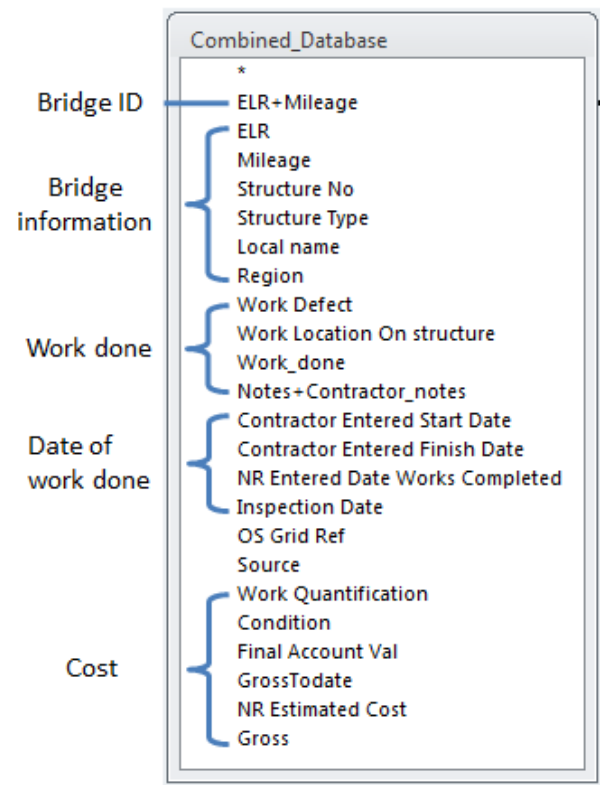

Figure 1: Information fields in a single working database after the merging and cleansing of all different datasets

The data used in this study on the UK railway system contains historical work done reports for their 30,000 railway bridges. There are approximately 35,000 entries which record the work carried out on bridge components from 2002 to 2011. Prior to analysis, the dataset is cleansed and filtered to query only relevant data for each bridge sub-structure. It is worth noting that as the dataset comes from different sources, it is poorly structured and was merged from minor interventions (MONITOR), major interventions (CAF), inspection and condition monitoring (SCMI) databases. Also data entries are free text fields rather than descriptive word, thus effort had to be made to ensure that the data are merged and extracted sensibly. The final working dataset then contains information about each individual asset. It contains not only the structure information, but also the details of the maintenance work that have been done, associated costs, previous inspections, and any other work related records. The nature of the resulting sparse data means that there are cases where there is a record indicating a repair has happened but there were 
no inspections either before or after a repair. In this case, the time when the bridge was built was used to calculate the censored lifetime data which is the time between the recorded repair and when the component was installed or last repaired.

\section{Deterioration modelling}

Different components experience different levels of degradation. Similar components can be grouped together under the assumption that they share a similar degradation process and their lifetimes can be treated as belonging to a homogenous sample. Hence the components are grouped in term of component type and material for the degradation analysis.

\subsection{Life time analysis}

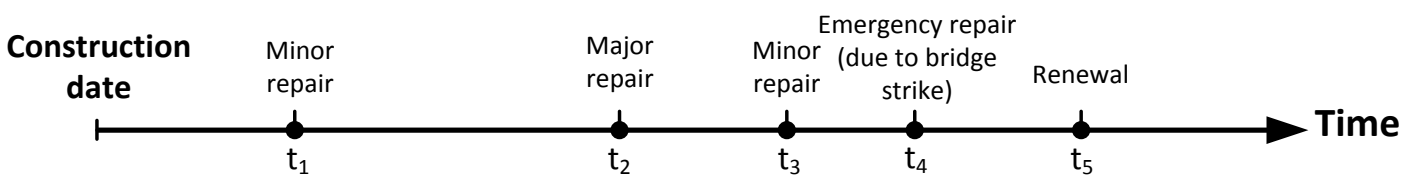

Figure 2: Timeline of historical work done on a bridge component

The degradation of a bridge element is analysed by studying the historical maintenance records throughout its lifetime and analysing the time between these interventions. Figure 2 illustrates a typical bridge component lifetime starting from when the bridge was constructed until the current date showing all the repairs that were carried out.

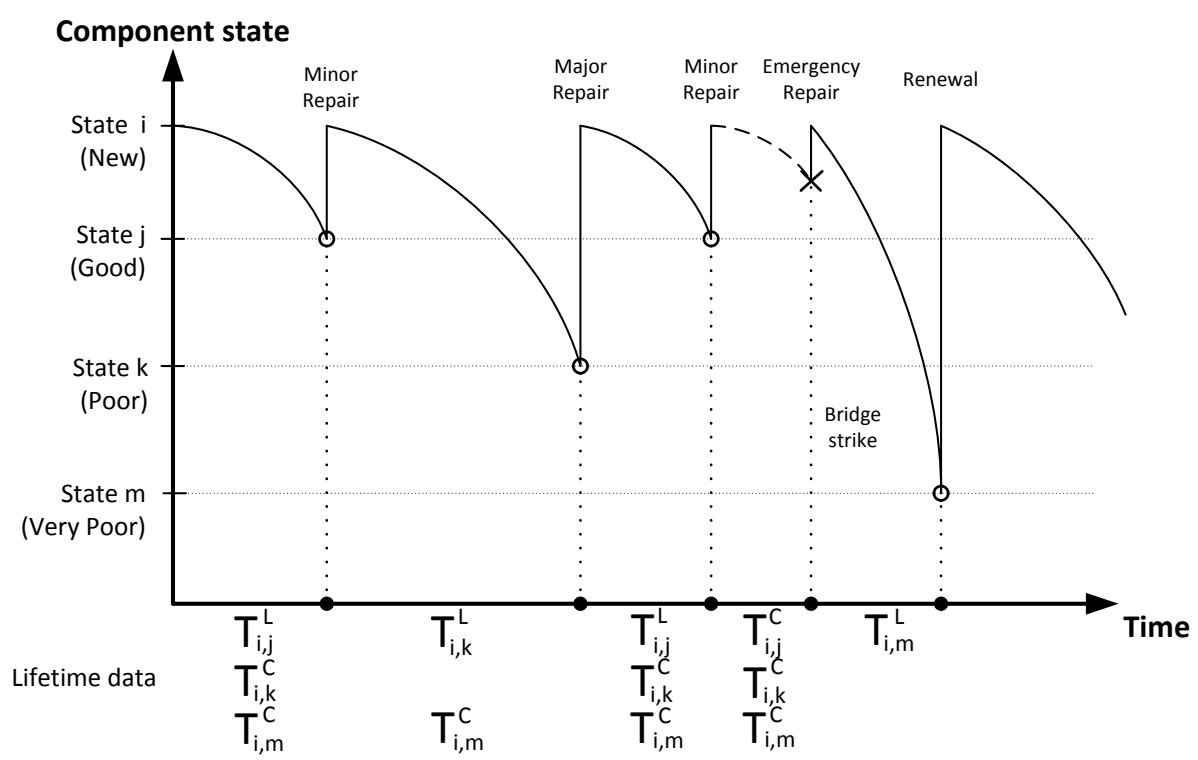

Figure 3: Typical deterioration pattern and historical work done on a bridge component 
Assuming that interventions restore the component condition back to the as good as new condition, the deterioration process can be seen in Figure 3. The time to reach the good (state j), poor (state $k$ ) and very poor (state $m$ ) state from new (state $i)$ are given as $T_{i, j}^{L}, T_{i, k}^{L}$ and $T_{i, m}^{L}$ respectively. In lifetime analysis, these times are often called the time to failure, however, in this paper, the time to failure indicate the time to an event when the component has reached the condition that triggers a repair and does not mean the physical failure of a bridge component. It is important when analysing the lifetime data of a component to account for both complete data, $T^{L}$ and censored data, $T^{C}$. Complete data indicates the time of reaching any degraded state from the as new state. Censored data is incomplete data where it has not been possible to measure the full lifetime. This may be because the component was repaired or replaced, for some reason, prior to reaching the analysed degraded condition and so the full life has not been observed. The components life is however known to be at least $T^{C}$. Figure 3 shows how the complete and censored times are identified. In particular, the time between any repair and a minor repair is a complete time indicating the full life time of the component reaching the degraded state where minor repair is required from the 'as new' state. This time is also the censored time for the major repair or replacement since it measures at least the time until these states are encountered. The process of extracting these lifetimes is automated using an algorithm developed in MATLAB. In this process, the time between different maintenance actions happened in a component life is calculated and is sorted accordingly.

\subsection{Distribution fitting}

Having obtaining the lifetime data for the bridge components, components of the same type and materials can be grouped together and the data fitted with a distribution. A range of distributions can be used (e.g. Weibull, Lognormal, Exponential, Normal). The goodness-of-fit test is used to compare the fitness of these distributions. The test involves visual observation of the probability plot and the conduction of a statistic test (Anderson-Darling test ${ }^{[18]}$ ). The twoparameter Weibull distributions were found to be the best fitted distribution in most of the cases, this agrees with the fact that Weibull is well known for its versatility to fit life-time data, and is a commonly used distribution in life data reliability analysis. For the two-parameter Weibull distribution, the expression for the probability density function is:

$$
\begin{gathered}
f(t)=\frac{\beta}{\eta}\left(\frac{t}{\eta}\right)^{\beta-1} e^{-\left(\frac{t}{\eta}\right)^{\beta}} \\
f(t) \geq 0, \beta \geq 0, \eta \geq 0
\end{gathered}
$$

$\beta$ is the shape parameter

$\eta$ is the scale parameter 
The scale parameter or characteristic life, $\eta$ is defined as being the time at which $63.2 \%$ of the population reached the modelled condition. The shape parameter, $\beta$ gives an indication of the rate of the deterioration process. The shape parameter determines whether the deterioration rate (hazard rate) is decreasing $(\beta<1)$, constant $(\beta=1)$, or increasing $(\beta>1)$. An increasing hazard rate means that at any time, the longer the bridge component has been in a condition state, the increasing likelihood of it degrading in the following year. The Weibull distribution's parameters are determined using rank regression. With the shape and scale parameter of the Weibull distribution derived, we now have a distribution that statistically models the degradation process of a bridge element in terms of the times it takes to degrade from the 'as new' state to degraded condition states.

The disadvantage when studying lifetime data is that it requires a significant amount of data to allow a distribution to be fitted with high confidence. The nature of a bridge structures is that deterioration is slow and so operating for long periods of time sometimes results in a very few or no repairs. In the cases where the data were neither available nor enough to allow a distribution to be fitted, a simple estimation ${ }^{[19]}$ can be used to estimate the degradation rates of a bridge component. In this estimation, the degradation process of bridge components is assumed to follow an exponential distribution, and the degradation rate is estimated as the reciprocal of the mean time to repair. The Weibull distribution can still be used to describe the degradation process with the beta value set to one and the eta value set to equal the estimated degradation rate.

\subsection{Estimation of single component degradation rate based on historical data provided for a group of similar components}

One problem encountered when analysing historical data for components which are one of several of the same type on the structure since the records do not identify work done on individual elements. For example, historical records often indicate a maintenance action was performed on a girder, however it is not possible to know which one. When applying the method described above to these data, the degradation rates obtained would be for the group of girders. These historical records did not provided enough information to identify a particular element that maintenance action was performed on. It is possible to estimate the degradation process for a single girder given these data. Assuming each of the girders behaves in the same way i.e. they have the same degradation characteristic. For examples, consider the situation for 2 girders and the times that girder 1 and 2 degrade to the intervention states are governed by Weibull distribution $\left(\beta_{2}, \eta_{2}\right)$. It is required to estimate the values of $\left(\beta_{2}, \eta_{2}\right)$ given that the values of $\left(\beta_{1}, \eta_{1}\right)$ are obtained using the method described in the previous section. 


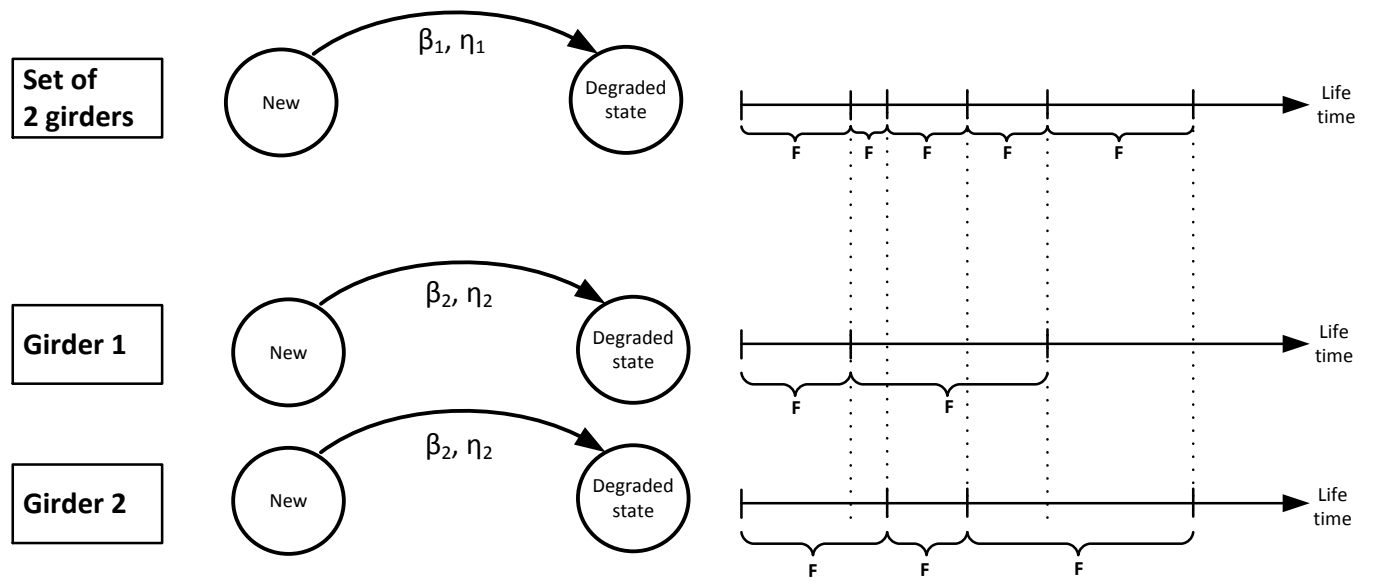

Figure 4: Single component degradation rate

Distributions of times for girder 1 and girder 2 to reach the degraded state from the new state can be generated as demonstrated in the time line shown in Figure 4. By combining these times and fitting a distribution, it is expected to obtain a distribution with the parameters very close to $\left(\beta_{1}, \eta_{1}\right)$. Thus an exhaustive search can be carried out to find the appropriate Weibull distribution $\left(\beta_{2}, \eta_{2}\right)$. The sequence of the search is described below:

1. For a range of $\left(\beta_{2}, \eta_{2}\right)$ values, complete life times for girder 1 and girder 2 are sampled. The life time is sampled until a certain simulation time is reached and the process is repeated for a number of generations.

2. The life times for girder 1 and girder 2 are combined together and then a Weibull distribution is fitted to the data where the parameters $\left(\beta_{1}^{\prime}, \eta_{1}^{\prime}\right)$ are obtained.

3. The most appropriate $\left(\beta_{2}, \eta_{2}\right)$ values is selected to produce $\left(\beta_{1}^{\prime}, \eta_{1}^{\prime}\right)$ so that $\left(\beta_{1}^{\prime}-\beta_{1}\right)$ AND $\left(\eta_{1}-\eta_{1}^{\prime}\right)$ are minimised.

Whist it is a recognised that if girder 1 and 2 deteriorate according to a Weibull distribution, hat the combined times will not be Weibully distributed. This is sufficiently accurate for this study.

\section{Results and Discussions}

\subsection{Bridge types and major elements studied}

Bridges are classified into underbridges and overbridges. Each type of the bridge is further categorised into their main material: masonry, concrete, metal and other (timber, composite, etc.). The method of bridge component lifetime evaluation used in this research is demonstrated by application to the metal underbridges asset group. The reason for this is that, metallic bridges deteriorate faster when comparing with concrete and masonry bridges making them one of the most critical asset groups. Data are available for four main 
bridge components which are bridge deck, girder, bearing and abutment (Figure 5). These components are also studied according to different material types (metal, concrete, masonry, timber).

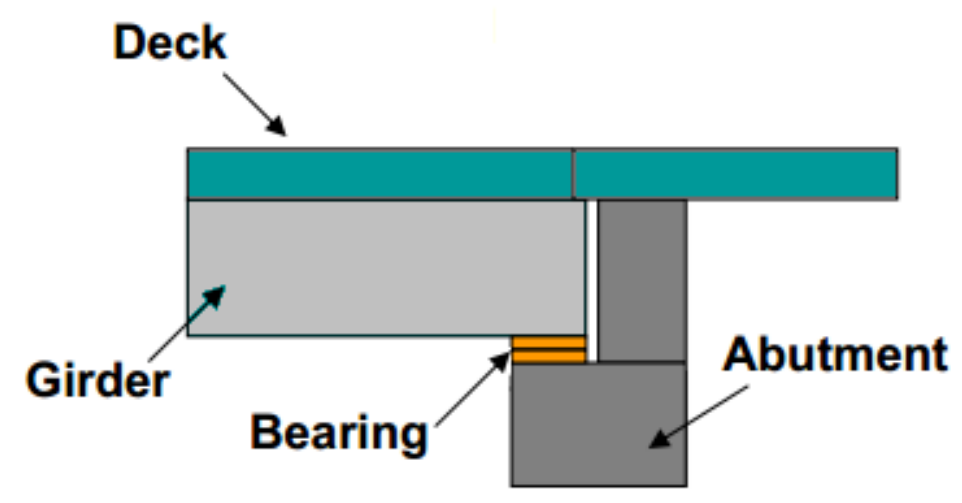

Figure 5: Bridge components studied

\subsection{Metal main girder}

There are a total of more than 37,000 metal bridge main girder components in the metal underbridge population and around $80 \%$ of them are in the good and poor condition (Figure 6). Since the number of the data containing historical work done are quite low, there are only 604 sets of girders that were actually studied in the analysis. This means that only $1.6 \%$ of the population that contained useful information which could be used in the analysis. Figure 7(a) shows the distribution of all types of work that were recorded in the database. Although there are a significant number of records on minor and major intervention, there are only 4 entries which recorded the renewal of bridge main girders. Components in the same condition state may exhibit different types of defects which would require specific repair work. Based on the detailed work recorded in the database, it is possible to know in each these work categories (minor, major repair, replacement, servicing), what type of renovation work is carried out. Figure 7 (b) and (c) show the distributions of the specific work performed for the minor and major repair categories. Steelwork repairs appear most frequently in both minor and major repair categories, however, they addressed different severity and extent of the defects. 


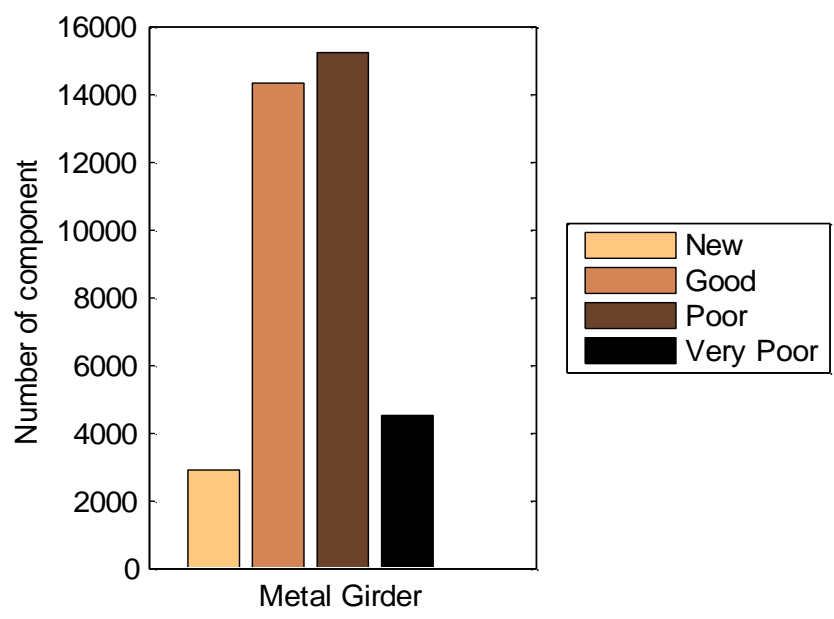

Figure 6: Condition distribution of metal main girders

(a) All types of records

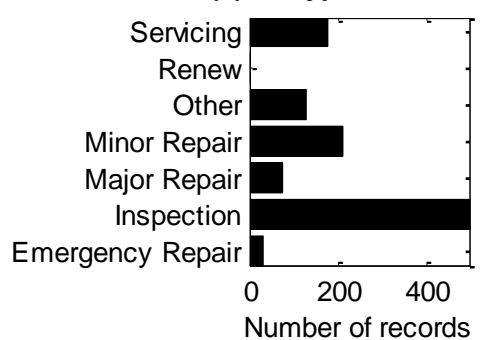

(c) Major Repair

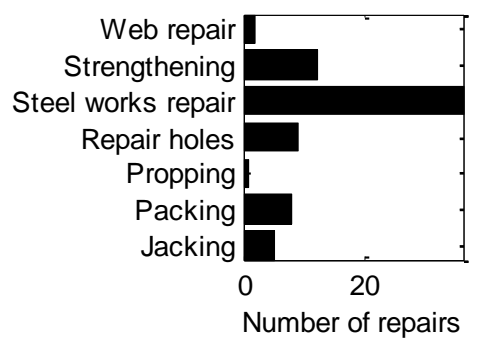

(b) Minor Repair

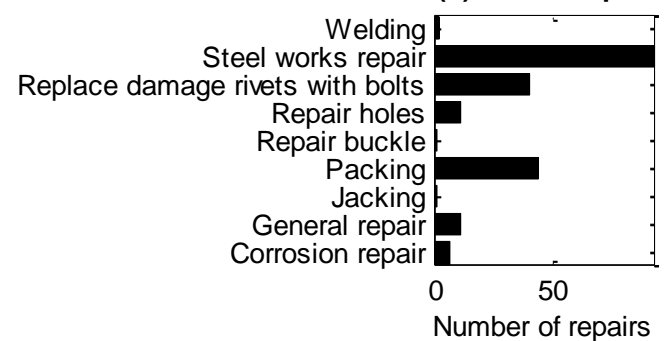

(d) Servicing

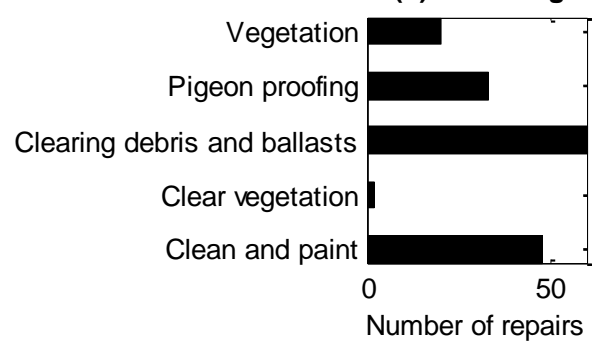

Figure 7: Distributions of specific works for Metal Girder

\section{Distribution fitting}

Figure 8 shows the Weibull probability plot for the durations of a set of two girders reaching the good condition from the 'as new' condition. The plot shows a very good fit with the Correlation coefficient very close to 1 . Figure 9 shows the probability plot of the distribution of times for a group of girders to reach a poor condition. It can be seen clearly that there are much less data for the analysis in this case resulting in wider confidence intervals on the best-fit plot. There were only 4 recorded instances of the main girder replacement, thus preventing the derivation of the lifetime distribution in this case. Therefore, the cruder method of assuming the degradation process of bridge components follows an exponential distribution, and the degradation rate is estimated as the reciprocal of the mean time to repair was employed to 
estimate the rate of girder replacement. All distribution parameters obtained for pairs of girders are shown in the graphs and are tabulated in Table 2.

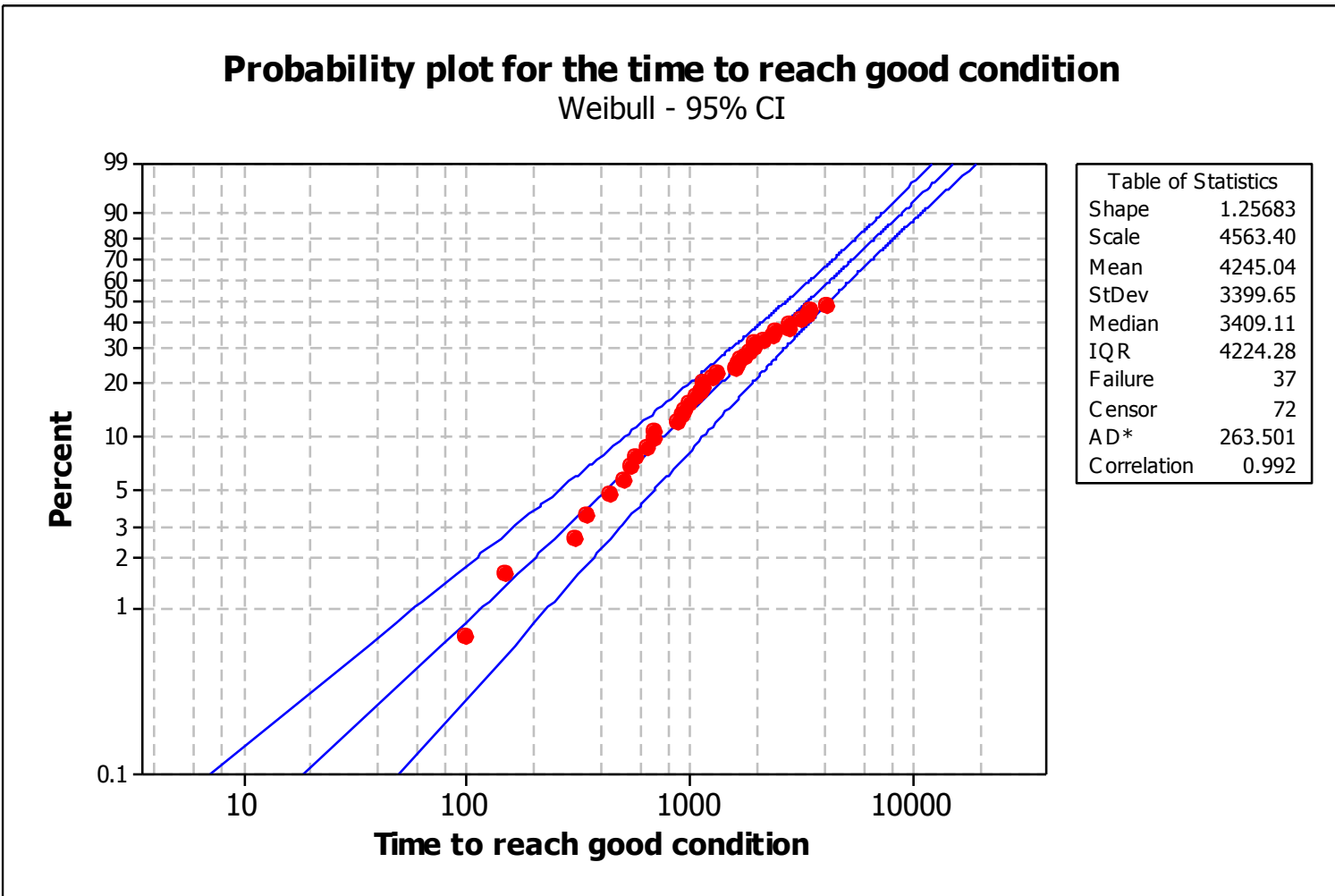

Figure 8: Probability plot of the time the girder reaches the good condition where minor repair is needed.

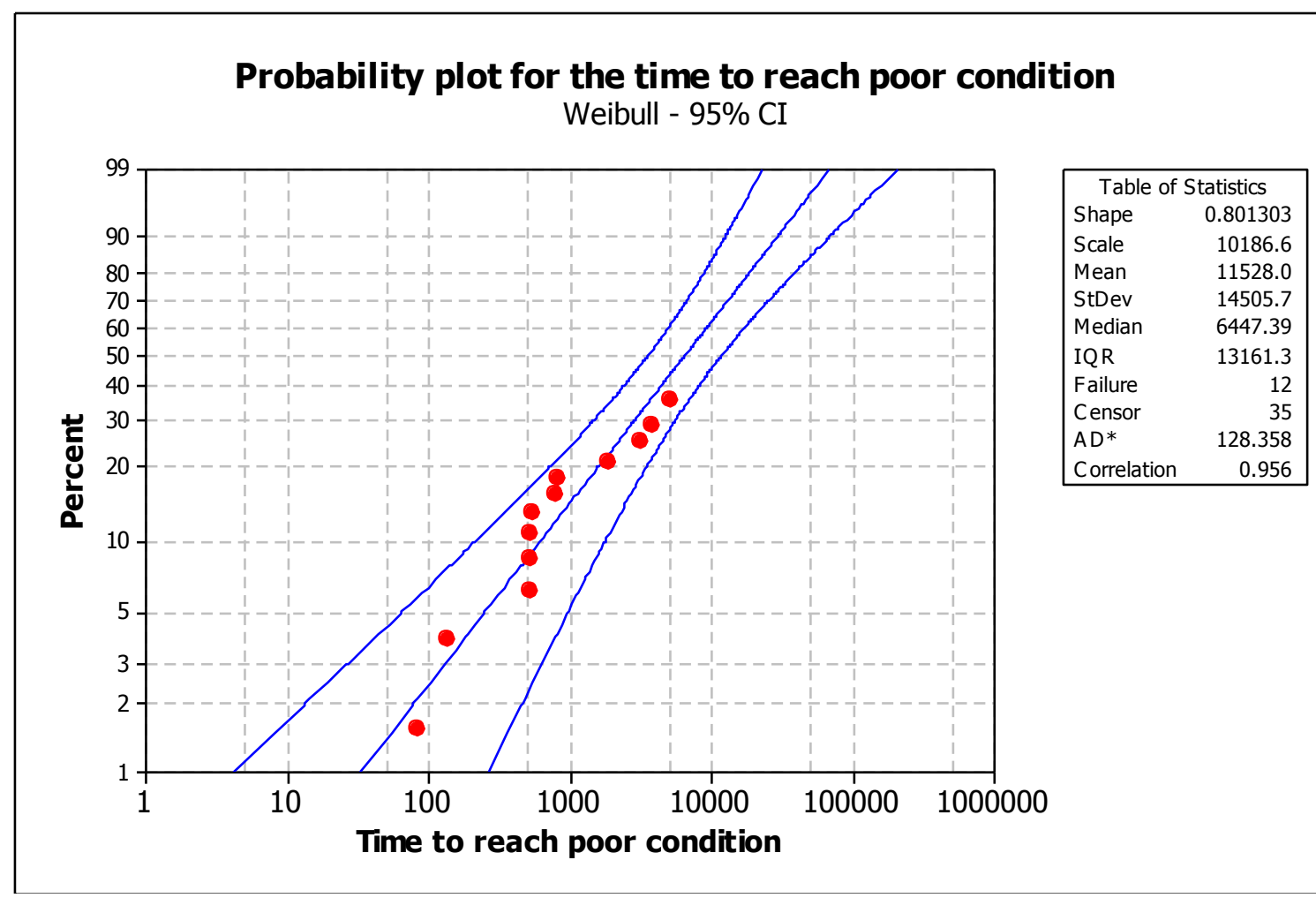


Figure 9: Probability plot of the time the girder reaches the good condition where minor repair is needed.

In addition to the deterioration process for the pairs of girders, Table 2 also shows the estimated distribution parameters to model the degradation process of a single main girder. It is worth noting that the data used in the analysis are mostly on metal half through girder bridges. The riveted metal half though girder bridge is the most common form of metal bridge on the railway system. Its common structural form is of two I-shape girders fabricated from riveted wrought iron or steel plates with deck spanning laterally between them. Therefore, where the data used do not identify the work done on individual elements, it has been generalised that these records are for pairs of girders. The shape parameter obtained for the degradation process of a single girder from the new to the good condition is greater than one, this indicates that the deterioration rate is increasing with time (wear-out characteristics). The failure rate functions are plotted in Figure 10, which give the instantaneous degradation rate of the main girder given the time it has been residing in the as new condition. It can be seen that the rate of reaching the good condition from the 'as new' condition is increasing as indicated by the value of the beta parameter obtained, and the rate increases by almost 8 times after the first 20 years. Unexpectedly, the rate of reaching the poor condition shows a slight decrease, it is suspected that the lack of data has resulted in the decreasing rate of failure with time. In contrast, the rate of main girder replacement is fairly constant with a slight increase with the mean time to replace a girder is about every 143 years.

\begin{tabular}{|c|c|c|c|c|c|c|c|}
\hline \multicolumn{6}{|c|}{ Weibull fitting (Weibull 2-parameter) } & \multicolumn{2}{|c|}{ Number of data } \\
\hline $\begin{array}{c}\text { Bridge } \\
\text { component }\end{array}$ & Material & Condition & Beta & $\begin{array}{c}\text { Eta } \\
\text { (year) }\end{array}$ & $\begin{array}{l}\text { Mean } \\
\text { (year) }\end{array}$ & Complete & Censored \\
\hline \multirow{3}{*}{$\begin{array}{c}\text { Girder } \\
\text { (set of two) }\end{array}$} & \multirow{3}{*}{ Metal } & Good & 1.257 & 12.50 & 11.63 & 37 & 72 \\
\hline & & Poor & 0.801 & 27.91 & 31.58 & 12 & 35 \\
\hline & & Very Poor & 1.000 & 116.84 & 116.84 & 3 & 1 \\
\hline \multirow{3}{*}{$\begin{array}{c}\text { Girder } \\
\text { (single) }\end{array}$} & \multirow{3}{*}{ Metal } & Good & 1.71 & 23.39 & 20.86 & - & - \\
\hline & & Poor & 0.87 & 44.27 & 47.49 & - & - \\
\hline & & Very Poor & 1.14 & 149.63 & 142.77 & - & - \\
\hline
\end{tabular}

Table 2: Distribution parameters obtained from the life time study for metal girder. 


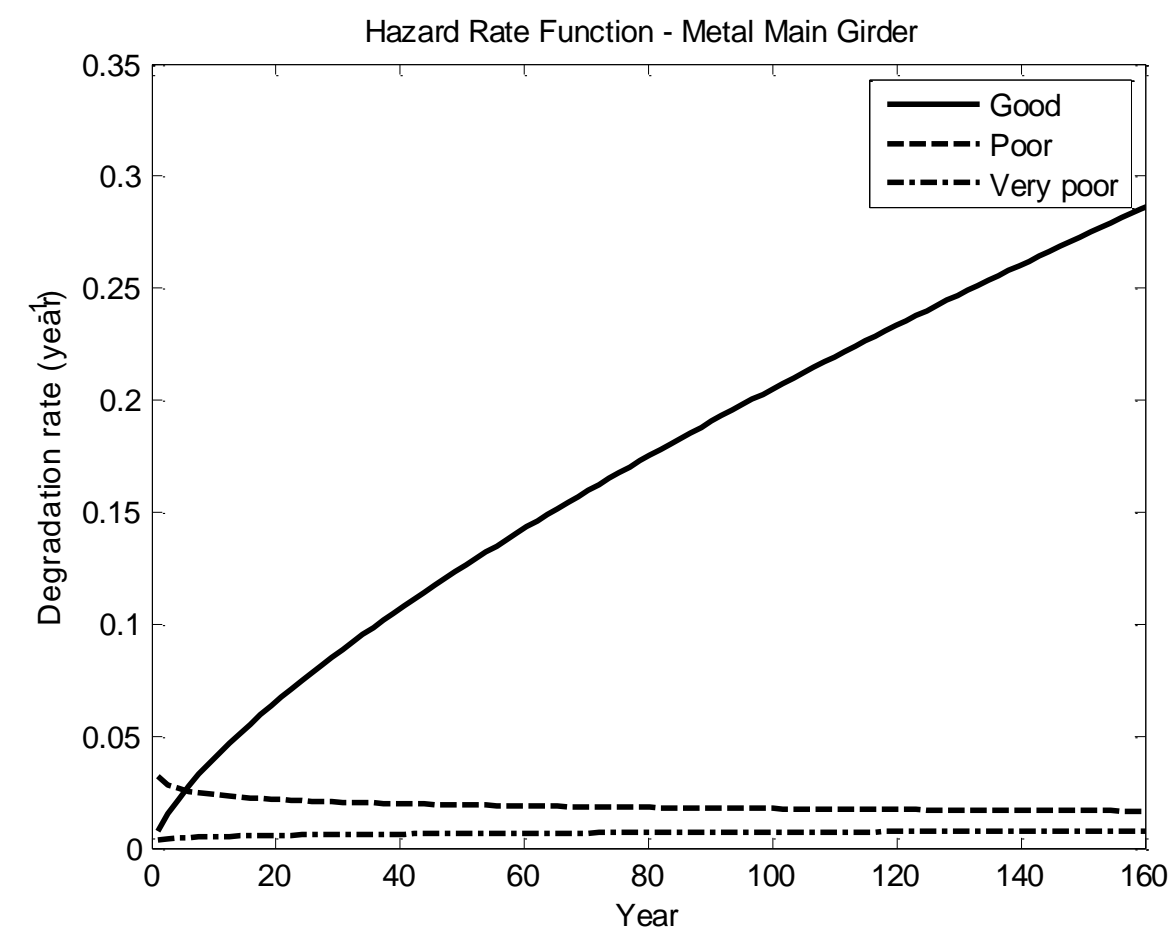

Figure 10: Hazard rate function which shows the rates of reaching degraded conditions at different life-time.

\subsection{Bridge decks}

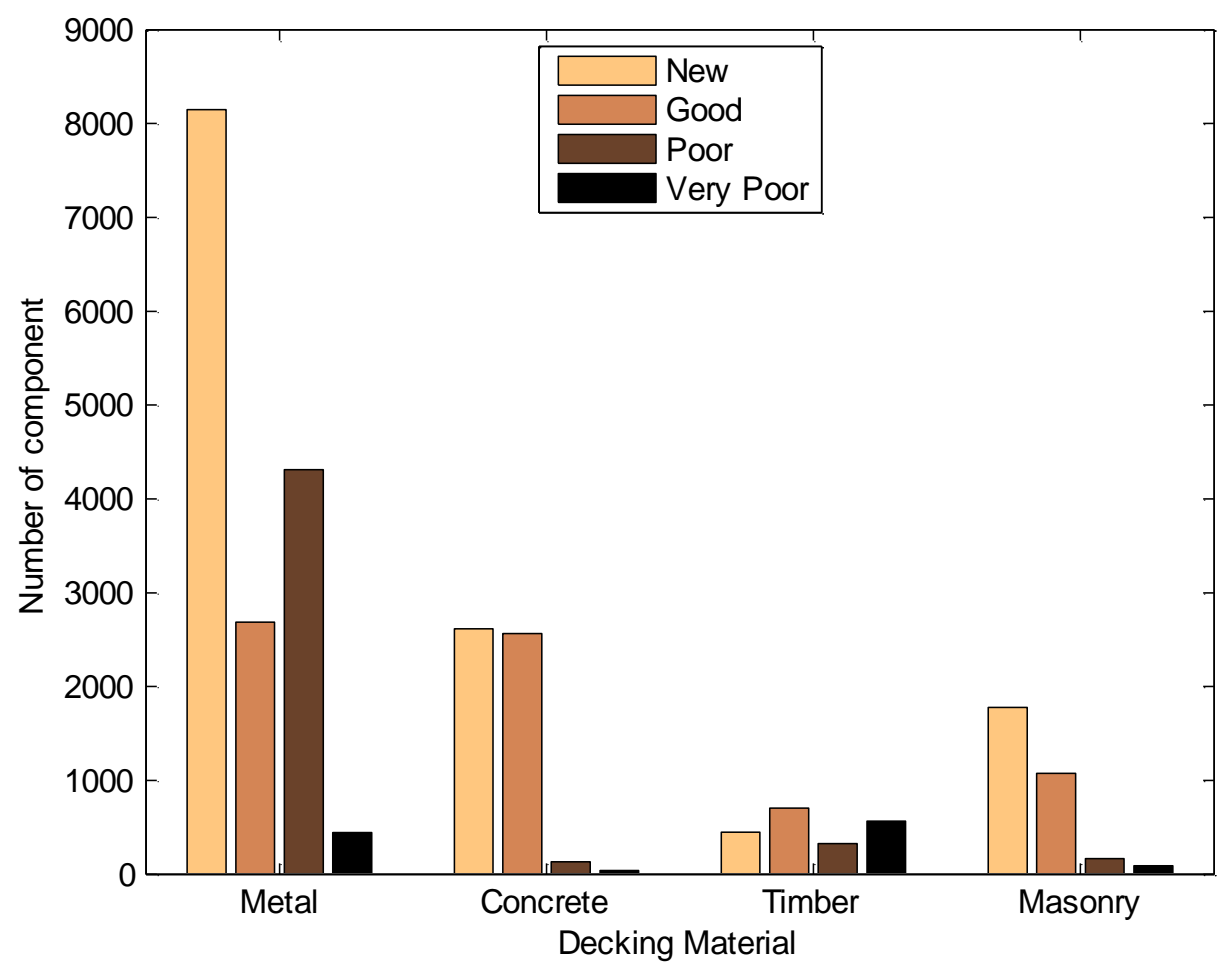

Figure 11: Condition distribution of bridge decks

There are four different types of bridge deckings used for metal underbridges. Metal is the most popular decking material with 15,589 metal decks with almost three times more than the population of concrete deckings, seven 
times more than timber decks and five times more than decks made of masonry. Figure 11 shows that, the current condition distribution varies according to the different bridge deck materials. Almost the entire population of concrete decks are in the new and good condition with only about $1 \%$ of the population is in the very poor condition that would need replacement. Metal decks have a different distribution with over $50 \%$ of the population in the 'as new' condition, $17 \%$ and $30 \%$ are in the 'good' and 'poor' states which would be restored by minor and major interventions respectively. High deterioration rates combined with the fact that timber deck was once a popular choice of decking materials shows that the condition of timber decks is quite evenly spread. Masonry decks, whist mentioned, will not be featured in the analysis due to there no being enough failure data available to support the study. Table 3 tabulates the Weibull distribution parameters obtained from the analysis for the three types of bridge deck: metal, concrete and timber. The results show that concrete decks are the most resilient of all deck types with the longest mean time to reach any degraded state. In contrast, timber decks have very short lifetimes of reaching degraded states with a mean time to degrade to a poor condition of around 6.5 years. Interventions required for timber decks would be sooner than for other deck types. The results for each bridge deck types are discussed in more detail in the next sections.

\begin{tabular}{|c|c|c|c|c|c|c|c|c|}
\hline \multicolumn{7}{|c|}{ Weibull Fitting (Weibull 2-parameter) } & \multicolumn{2}{|c|}{ Number of data } \\
\hline $\begin{array}{c}\text { Bridge } \\
\text { component }\end{array}$ & Material & Condition & Intervention & Beta & $\begin{array}{c}\text { Eta } \\
\text { (year) }\end{array}$ & $\begin{array}{l}\text { Mean } \\
\text { (year) }\end{array}$ & Complete & Censored \\
\hline \multirow{9}{*}{ DECK } & & Good & Minor Repair & 1.265 & 10.28 & 9.54 & 16 & 67 \\
\hline & Metal & Poor & Major Repair & 1.038 & 20.00 & 19.71 & 10 & 58 \\
\hline & & Very Poor & Replacement & 1.009 & 28.47 & 28.36 & 14 & 72 \\
\hline & & Good & Minor Repair & 1.082 & 19.09 & 18.52 & 3 & 7 \\
\hline & Concrete & Poor & Major Repair & 1.000 & 26.67 & 26.67 & 0 & 4 \\
\hline & & Very Poor & Replacement & 0.976 & 34.26 & 34.63 & 2 & 10 \\
\hline & & Good & Minor Repair & 1.312 & 3.99 & 3.68 & 12 & 5 \\
\hline & Timber & Poor & Major Repair & 1.371 & 7.13 & 6.52 & 5 & 6 \\
\hline & & Very Poor & Replacement & 1.501 & 6.12 & 5.52 & 27 & 40 \\
\hline
\end{tabular}

Table 3: Distribution parameters obtained from the life time study for metal decks.

\subsection{Metal deck}

Figure 12 shows the distribution of all the specific interventions recorded that were used for the analysis. Each intervention category contains data ranging between 70 and 90 records, however most of the data are censored lifetime data. Useful data which indicate complete lifetime durations are only about $15 \%$ of the sample size i.e. about 10-16 complete lifetime data. Figure 13

to

Figure 15 show the probability plots of the times to reach each degraded state where a Weibull distribution is fitted and the distribution parameters are obtained. The plots show a very good fit of the Weibull distribution to the data with high correlation coefficient. The shape parameters obtains for a metal deck reaching a poor and a very poor state are very close to 1 . Distinctively, the rate of metal decks moving from a new condition to a good condition is 
increasing from 0.06 metal decks per year to about 0.18 after 60 years. Thus it is three times more likely for a 60 years old metal deck to require a minor repair comparing with the new metal deck.
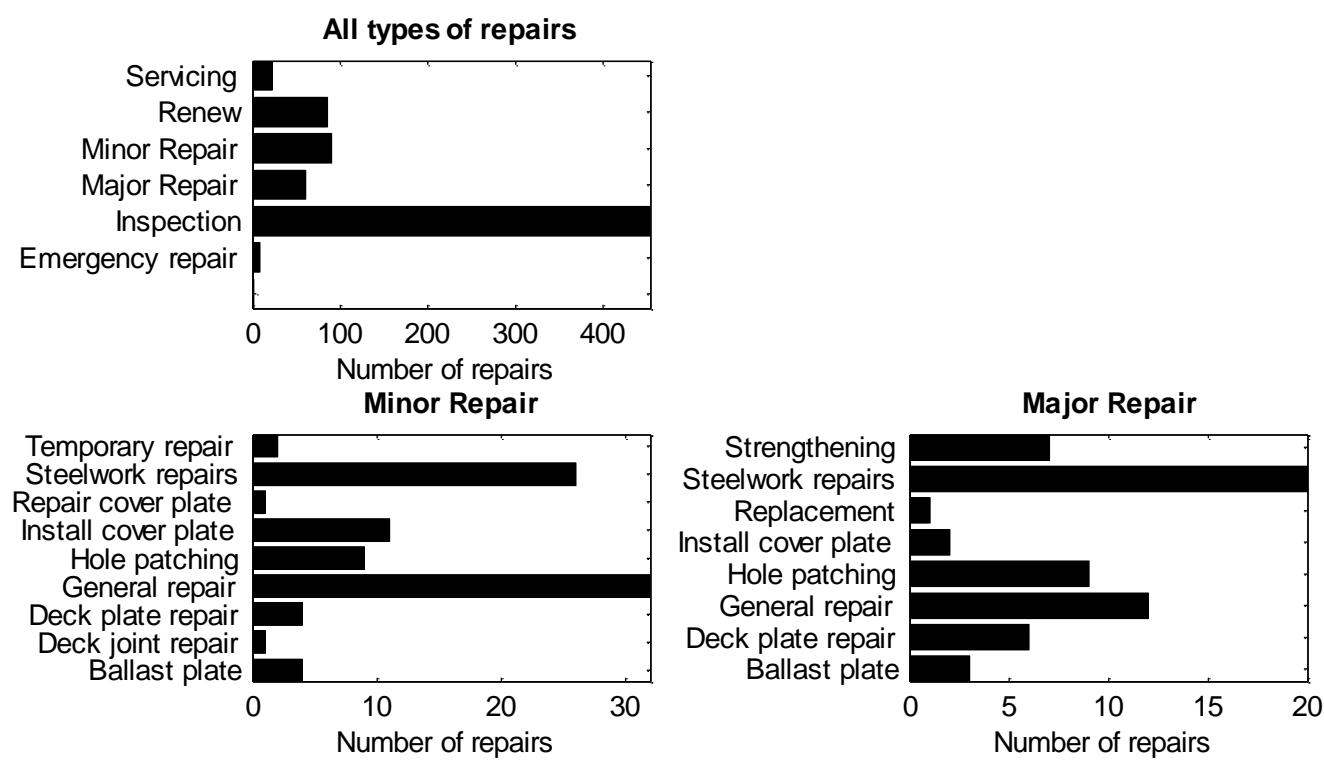

Figure 12: Distributions of specific works for metal deck.

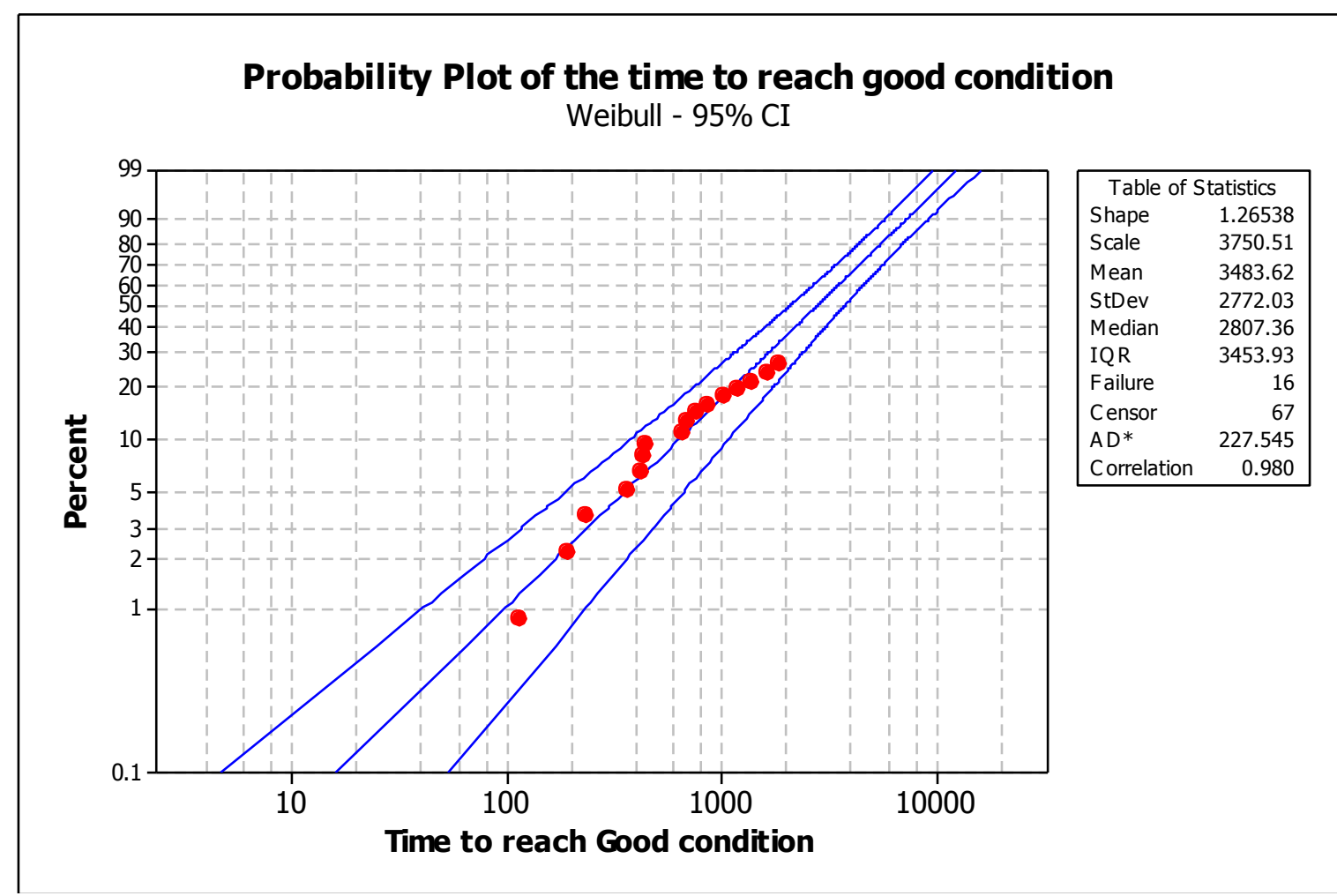

Figure 13: Probability plot of the time a metal deck reaches the good condition where minor repair is needed. 


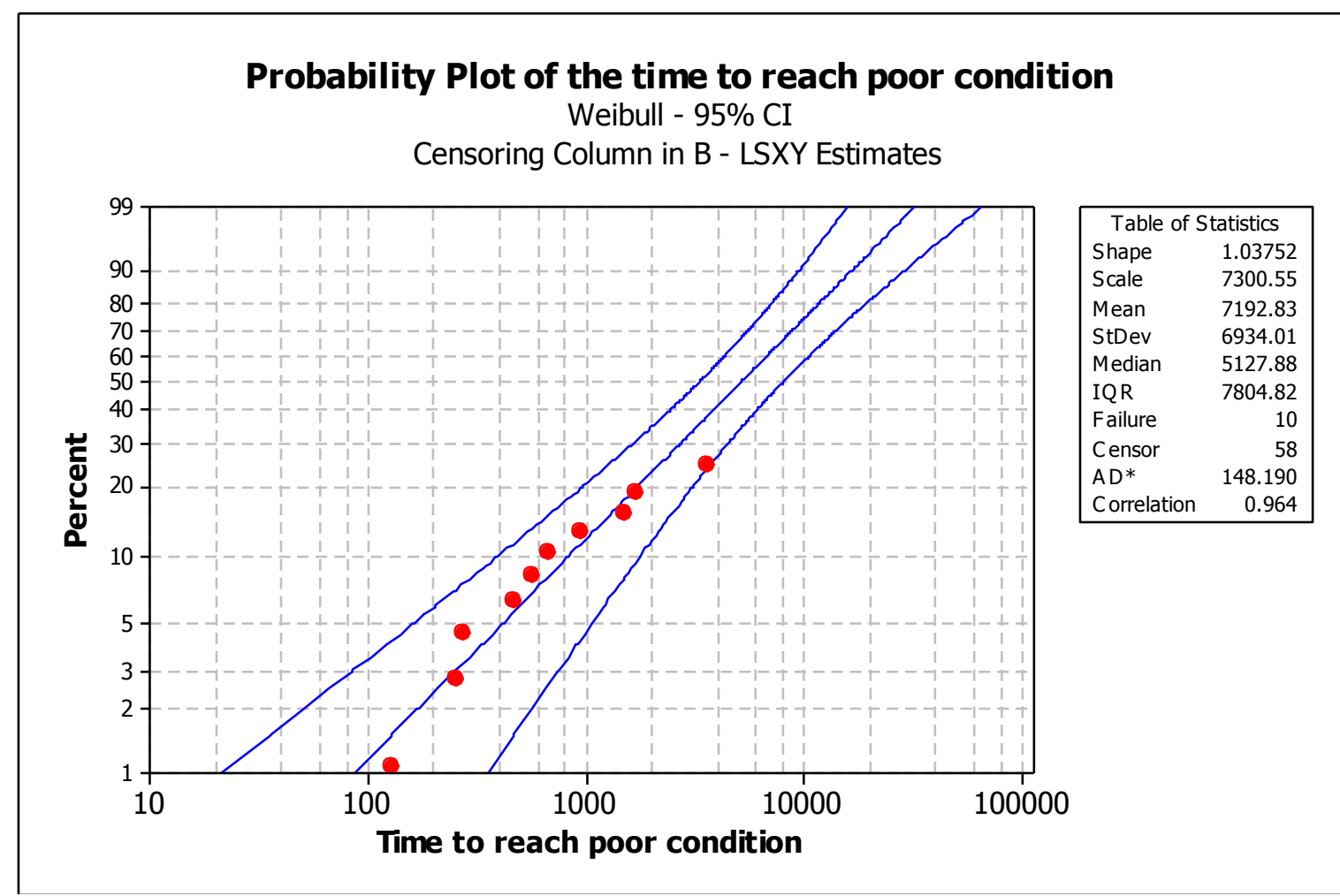

Figure 14: Probability plot of the time a metal deck reaches the poor condition where major repair is needed.

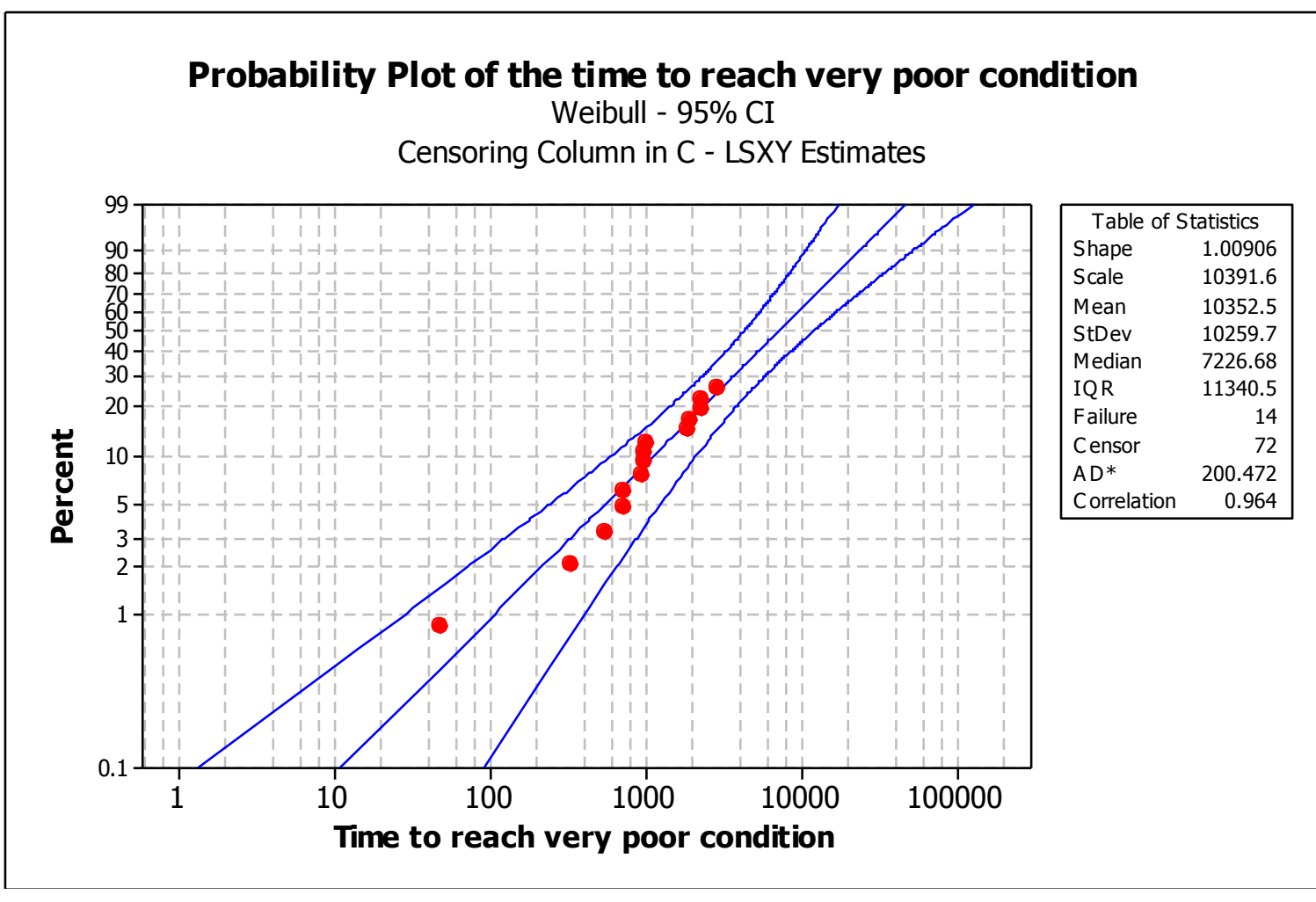

Figure 15: Probability plot of the time a metal deck reaches the very poor condition where replacement is needed. 


\subsection{Concrete deck}

As demonstrated in Figure 11, the majority ( $>95 \%$ ) of concrete decks are in the new and good conditions. This, combined with the relatively young age of the population, has resulted in a low number of repairs recorded for bridge concrete decks. There are only 18 minor repairs, 9 major repairs and 20 deck replacements as illustrated in Figure 16. Table 3 shows that the shape parameters obtained are very close to 1 in all cases, this suggests that the deterioration rates of the concrete decks are fairly constant over time. The characteristic life parameter of the concrete deck reaching any degraded conditions are the longest among all deck types. It can be seen that the time for $63.2 \%$ of the concrete decks to degrade to a good condition is about 19 years. This is almost equivalent to the characteristic time of the metal deck to degrade to a poor condition (20 years).

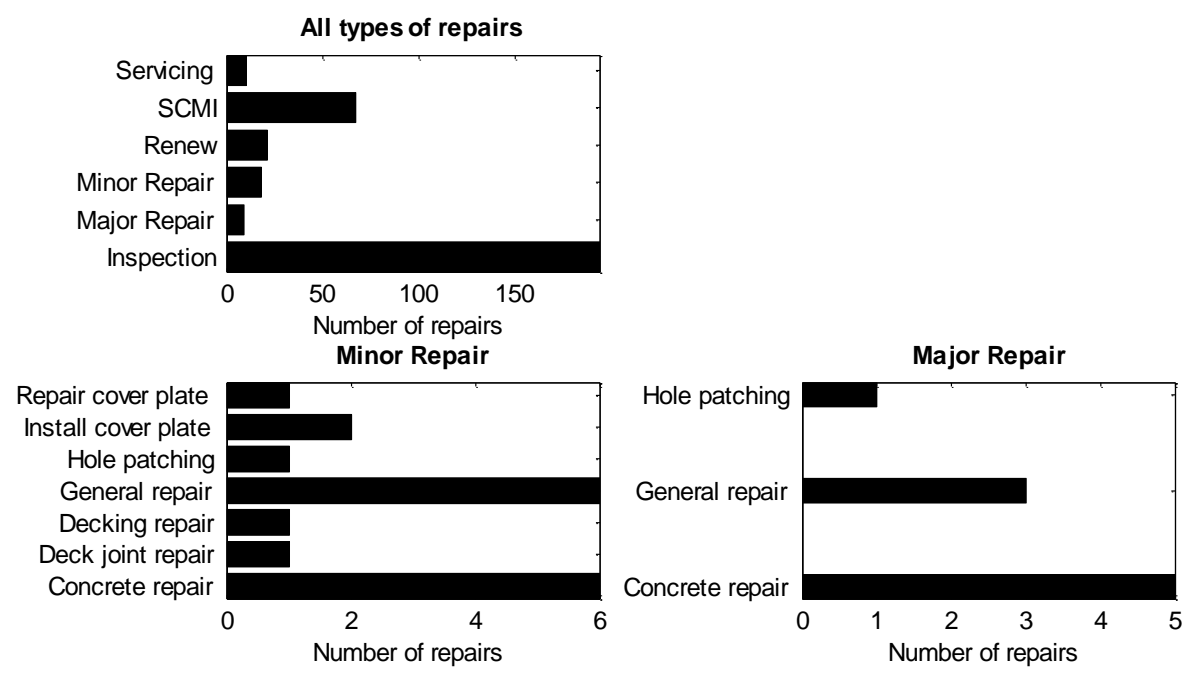

Figure 16: Distributions of specific works for concrete deck.

\subsection{Timber deck}

The timber deck results demonstrated a very short life comparing with the decks constructed of other materials. Also the rates for reaching different deteriorated conditions increase significantly with time. Timber materials have much shorter life span than metal and concrete, and once the material reaches a point of severe defects, the timber deck is usually replaced. This preferable option of repairs is demonstrated in Figure 17. The number of replacements recorded in the database (more than 100 timber deck replacements) is much greater than the number of times major repair were carried out (20 timber deck major repairs). Table 3 shows that the shape parameters obtained are around 1.3-1.5, this suggests that the deterioration rates of the timber decks increase over time and this is illustrated in Figure 18. 


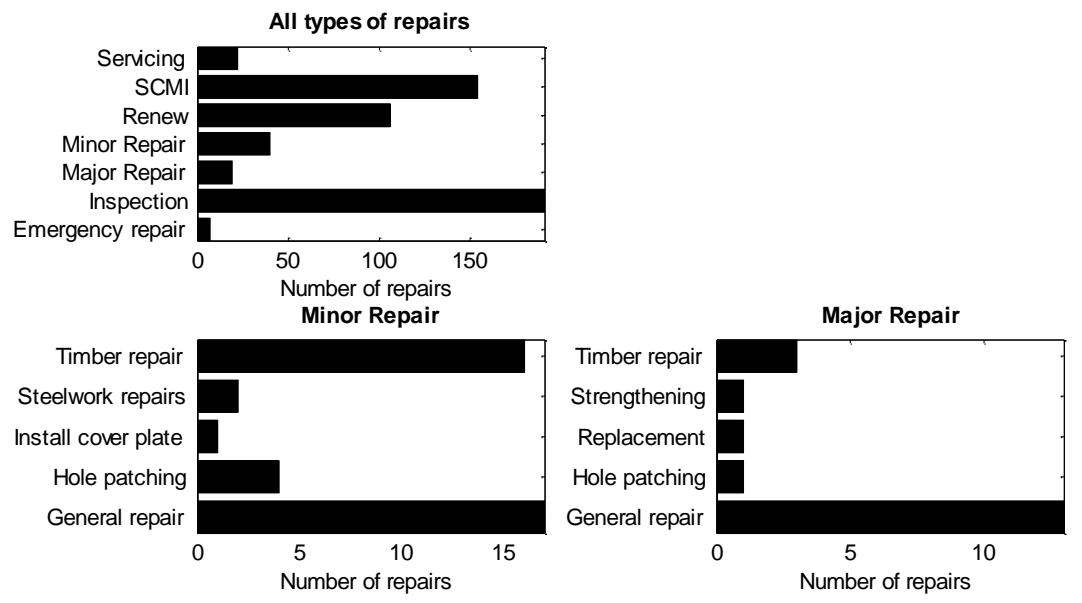

Figure 17: Distributions of specific works for timber deck

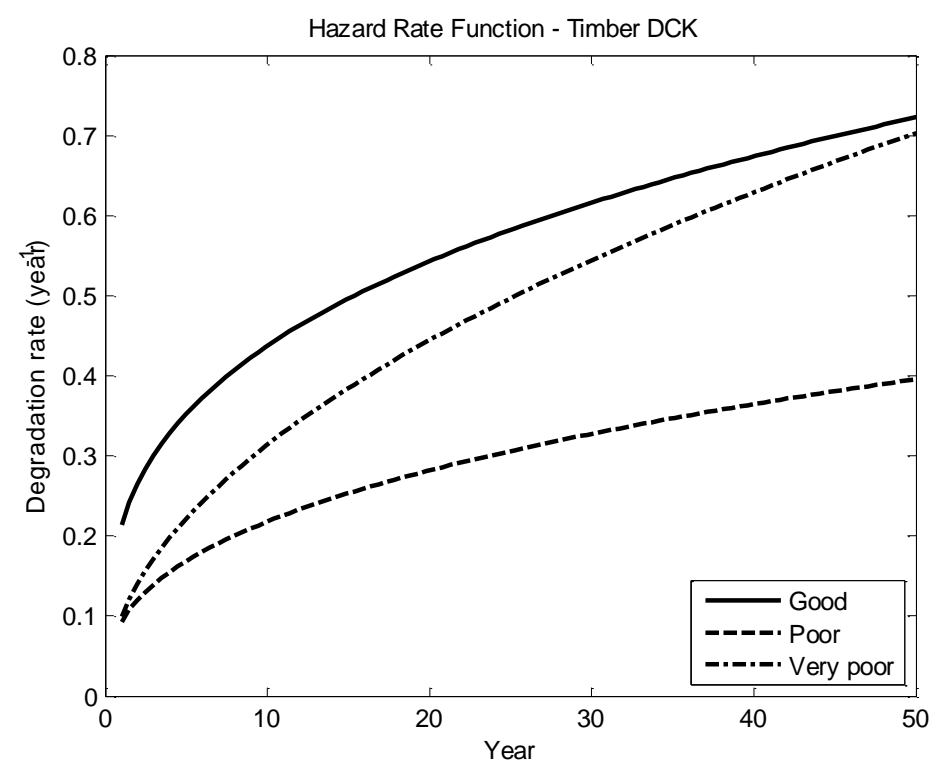

Figure 18: Hazard rate function which shows the rates of reaching degraded conditions at different life-time.

\subsection{Metal bearing}

\begin{tabular}{|c|c|c|c|c|c|c|c|c|}
\hline \multicolumn{7}{|c|}{ Weibull Fitting (Weibull 2-parameter) } & \multicolumn{2}{|c|}{ Number of data } \\
\hline $\begin{array}{c}\text { Bridge } \\
\text { component }\end{array}$ & Material & Condition & Intervention & Beta & $\begin{array}{c}\text { Eta } \\
\text { (year) }\end{array}$ & $\begin{array}{l}\text { Mean } \\
\text { (year) }\end{array}$ & Complete & Censored \\
\hline \multirow{3}{*}{ BEARING } & & Good & Minor Repair & 0.838 & 14.94 & 16.41 & 12 & 39 \\
\hline & Metal & Poor & Major Repair & 2.129 & 14.43 & 12.78 & 5 & 10 \\
\hline & & Very Poor & Replacement & 1.000 & 21.92 & 21.92 & 1 & 2 \\
\hline
\end{tabular}

Table 4: Distribution parameters obtained from the life time study for metal bearings.

The rate at which a bearing would require a minor repair is almost constant at about 0.1 every year. The data that indicates a bearing major repair is often extracted from an entry that carries information about other repair works on other components. Even though this entry is categorised in the database as 
major work, it might be that other works were major and the bearing repair might be opportunistic work. About $70 \%$ of bearing major repair data were extracted this way and since it is not possible to validate these entries, it is accepted that the data has influence these unexpected results.

\subsection{Masonry abutment}

\begin{tabular}{|c|c|c|c|c|c|c|c|c|}
\hline \multicolumn{7}{|c|}{ Weibull Fitting (Weibull 2-parameter) } & \multicolumn{2}{|c|}{ Number of data } \\
\hline $\begin{array}{c}\text { Bridge } \\
\text { component }\end{array}$ & Material & Condition & Intervention & Beta & $\begin{array}{c}\text { Eta } \\
\text { (year) }\end{array}$ & $\begin{array}{l}\text { Mean } \\
\text { (year) }\end{array}$ & Complete & Censored \\
\hline ABUTMENT & Masonry & $\begin{array}{c}\text { Good } \\
\text { Poor } \\
\text { Verv Poor }\end{array}$ & $\begin{array}{l}\text { Minor Repair } \\
\text { Major Repair } \\
\text { Replacement }\end{array}$ & $\begin{array}{l}1.000 \\
1.000 \\
1.000\end{array}$ & $\begin{array}{c}51.94 \\
100.87 \\
150.00\end{array}$ & $\begin{array}{c}51.94 \\
100.87 \\
150.00\end{array}$ & $\begin{array}{l}1 \\
1 \\
0\end{array}$ & $\begin{array}{l}9 \\
2 \\
1\end{array}$ \\
\hline
\end{tabular}

Table 5: Distribution parameters obtained from the life time study for metal abutments.

The results obtained indicate that abutment requires much less maintenance than other bridge elements with the mean time of an abutment to deteriorate to a point at which minor repair could be performed is about 52 years. There were no data to allow the rate of abutment replacement to be calculated, which again agrees with the fact that abutment almost never requires complete replacement, unless it is a complete demolition of the entire bridge due to upgrade or natural disaster.

\section{Summary}

This paper addresses the deficiencies of condition rating data used in bridge degradation modelling and presents a method of modelling the degradation of a bridge element by analysing its historical maintenance records. The life time of the component is calculated by the time the component takes to deteriorate from the 'as new' state to the degraded state where an intervention could be carried out. By gathering samples of the lifetime date for a component of the same type, a Weibull distribution is fitted to these data to model the deterioration process. In the case where the degradation process was determined for a group of main girders, an estimation method of obtaining the distribution of lifetimes for a single girder was also described. An empirical study was also carried out using real data to model the degradation process of several bridge main components (girders, decks, bearings and abutments). In conclusions, the presented method demonstrates that:

- Historical maintenance data can be used as an alternative approach to bridge degradation modelling.

- Life data analysis method can be applied to model the deterioration process of bridge elements. This method recognises the 'censored' nature of bridge lifetime data and incorporates these data into the modelling process. 
- Distributions of times of a component degrading to degraded states (good, poor and very poor) from the as new state can be obtained.

- The distributions obtained indicate that the deterioration rates of bridge elements are not necessarily constant, for most cases, the deterioration rates of the components increase slightly over time.

- The disadvantage when studying lifetime data is that it requires a significant amount of data to allow a distribution to be fitted for accurate modelling. The nature of a bridge structure operating for long period of time sometimes results in a very few or no repair data. However it is expected that with the increasing quality and quantity of the data, more accurate results can be obtained.

\section{Acknowledgement}

John Andrews is the Royal Academy of Engineering and Network Rail Professor of Infrastructure Asset Management. He is also Director of Lloyd's Register Foundation (LRF) ${ }^{1}$ for Risk and Reliability Engineering at the University of Nottingham. Bryant Le is conducting a research project funded by Network Rail. They gratefully acknowledge the support of these organisations.

\footnotetext{
${ }^{1}$ Lloyd's Register Foundation supports the advancement of engineering-related education, and funds research and development that enhances safety of life at sea, on land and in the air.
} 


\section{References}

1. Federal Highway Administration, Bridge inspector's reference manual : BIRM2012, [Washington, D.C.]; [Arlington, Va.]; Springfield, VA: U.S. Federal Highway Administration ; National Highway Institute; Available through the National Technical Information Service.

2. Jiang, Y. and K.C. Sinha, Bridge service life prediction model using the Markov chain. Transportation Research Record, 1989(1223): p. 24-30.

3. $\mathrm{Ng}, \mathrm{S}$. and F. Moses, Prediction of bridge service life using time-dependent reliability analysis. Bridge management, 1996. 3: p. 26-32.

4. Cesare, M.A., et al., Modeling bridge deterioration with Markov chains. Journal of Transportation Engineering, 1992. 118(6): p. 820-833.

5. Mishalani, R.G. and S.M. Madanat, Computation of infrastructure transition probabilities using stochastic duration models. Journal of Infrastructure Systems, 2002. 8(4): p. 139-148.

6. Morcous, G., Performance Prediction of Bridge Deck Systems Using Markov Chains. Journal of Performance of Constructed Facilities, 2006. Vol. 20(No. 2): p. 146-155.

7. DeStefano, P.D. and D.A. Grivas, Method for estimating transition probability in bridge deterioration models. Journal of Infrastructure Systems, 1998. 4(2): p. 56-62.

8. Sobanjo, J.O., State transition probabilities in bridge deterioration based on Weibull sojourn times. Structure and Infrastructure Engineering, 2011. 7(10): p. 747-764.

9. Agrawal, A.K. and A. Kawaguchi, Bridge element deterioration rates, 2009, New York State Department of Transportation.

10. Scherer, W.T. and D.M. Glagola, Markovian models for bridge maintenance management. Journal of Transportation Engineering, 1994. 120(1): p. 37-51.

11. Noortwijk, J.M.v. and H.E. Klatter, The use of lifetime distribution in bridge maintenance and replacement modelling. Computers and Structures, 2004. 82: p. 1091-1099.

12. Sobanjo, J., P. Mtenga, and M. Rambo-Roddenberry, Reliability-based modeling of bridge deterioration hazards. Journal of Bridge Engineering, 2010. 15(6): p. 671-683.

13. Network Rail, Structures Condition Marking Index Handbook for Bridges (formerly RT/CE/C/041), 2004.

14. Aktan, A.E., et al., Condition assessment for bridge management. Journal of Infrastructure Systems, 1996. 2(3): p. 108-117.

15. Ortiz-García, J.J., S.B. Costello, and M.S. Snaith, Derivation of transition probability matrices for pavement deterioration modeling. Journal of Transportation Engineering, 2006. 132(2): p. 141-161.

16. $\mathrm{Ng}, \mathrm{S}$. and F. Moses, Bridge deterioration modelling using semi-Markov theory. Structure Safety and Reliability, 1998. 1-3: p. 113-120.

17. Office of Rail Regulation, Annual assessment of Network Rail 2006-07, 2007.

18. Stephens, K.S., Reliability Data Analysis with Excel and Minitab2012: ASQ Quality Press.

19. Le, B. and J. Andrews, Modelling railway bridge asset management. Proceedings of the Institution of Mechanical Engineers, Part F: Journal of Rail and Rapid Transit, 2013. 